\title{
KNOWLEDGE AND ASSOCIATED FACTORS REGARDING HEALTH PROMOTIONAL MEASURES OF INFANT AMONG MOTHERS ATTENDING PEDIATRIC OPD OF UNIVERSAL COLLEGE OF MEDICAL SCIENCES
}

Chet Kant Bhusal, ${ }^{1}$ Sigma Bhattarai, ${ }^{2}$ Raju Kafle, ${ }^{3}$ Rubina Shrestha ${ }^{1}$

\begin{abstract}
INTRODUCTION

Infant and child health status depends upon knowledge of mothers regarding health promotional measures. This study aimed to determine knowledge and its associated factors regarding health promotional measures of infants amongst the mothers attending pediatrics outpatient department of Universal College of Medical Sciences Teaching Hospital, Bhairahawa, Rupandehi, Nepal.
\end{abstract}

\section{MATERIAL AND METHODS}

Hospital based cross-sectional study was conducted in Universal College of Medical Sciences Teaching Hospital, Bhairahawa, Rupandehi, Nepal among 414 mothers attending pediatrics outpatient department from September 2019 to March 2020. Bivariate and multivariate logistic regressions were used to explore associations between different factors with health promotional measures.

\section{RESULTS}

The mean age and family size was $25.89 \pm 4.81$ and $5.94 \pm 2.48$ respectively. A total of $73.2 \%$ mothers have good knowledge of health promotional measures. Mothers greater than 20 years (AOR =8.13, CI: 2.16-30.67), Dalit $(\mathrm{AOR}=0.02, \mathrm{CI}: 0.003-0.16)$, living in rural area $(\mathrm{AOR}=0.27, \mathrm{CI}: 0.08-0.61)$, family size greater than $5(\mathrm{AOR}=3.99, \mathrm{CI}$ : 1.37-11.59), below SLC education ( $\mathrm{AOR}=0.29, \mathrm{CI}:(0.09-0.88)$ and fathers with SLC and above education $(\mathrm{AOR}=25.40$, CI: 4.54-142.0), fathers engaged in non-agricultural work (AOR $=4.78, \mathrm{CI}: 1.80-12.68)$ and birth space of index child greater than two years $(\mathrm{AOR}=5.88, \mathrm{CI}$ : 1.48-23.55) were significantly associated with knowledge of health promotional measures.

\section{CONCLUSION}

Mothers' age, caste, residence, family size, education of parents, occupation of father and birth space of index child were found to be independent associated factors of knowledge. Thus policy makers should provide specific education regarding health promotional measures to both parents focusing rural area. Similarly, local Government needs to subsidize in reducing teenage marriage.

KEYWORDS Health promotional measures, Infants, Pediatric

1. Department of Community Medicine, Universal College of Medical Sciences, Bhairahawa, Nepal

2. Universal College of Nursing Sciences, Bhairahawa, Nepal

3. Department of Pediatrics, Universal College of Medical Sciences, Bhairahawa, Nepal

DOI: http//doi.org/10.3126/jucms.v8i02.34295

\author{
For Correspondence \\ Chet Kant Bhusal \\ Department of Community Medicine \\ Universal College of Medical Sciences \\ Bhairawaha, Nepal \\ Email: bhusalck3112@gmail.com
}




\section{INTRODUCTION}

Infancy is period of rapid physical, social growth and development. ${ }^{1}$ The need of health promotion is vital as infants are dependent and susceptible for cause of risky and vulnerable activities. ${ }^{2}$ Mother is primary for the promotion of health of infant. Health promotion of infants is done through breastfeeding, complementary feeding, immunization, growth monitoring and prevention of accident.

Due to the lack of knowledge on how to feed a child, infant and young children in many developing countries are vulnerable to malnutrition. ${ }^{3}$ A study conducted in Nepal showed that only $35 \%$ of the mothers had knowledge about initiation of breastfeeding within first hour of birth, $62 \%$ had known about exclusive breastfeeding timing and $81 \%$ had knowledge about appropriate time for introduction of complementary feeding and total time for breastfeeding. ${ }^{4}$

Infant mortality rate (IMR) of Nepal is 32 per 1000 live birth in 2016. . $^{5}$ More than half of the child deaths are preventable with access to cost-effective interventions of vaccination. Vaccination coverage of world has stagnant at $86 \%$ during the past year. ${ }^{6}$ Accident is an unintentional, undesirable, incidental, and unplanned injury, which could have been prevented. $^{7}$

Hence to maintain the proper health status of infant, proper health promotion is necessary. Health promotion of infant depends upon the level of knowledge and practice of mother. Although, there have been a burgeoning literature on various aspects of breastfeeding, complementary feeding, immunization and accidents among infants there are very few studies carried out to investigate the associated factors of knowledge regarding overall health promotional measures of infant. Hence this study aimed to determine knowledge and associated factors regarding health promotional measures of infant among the mothers attending pediatrics OPD of Universal College of Medical Sciences and Teaching Hospital (UCMS-TH) Bhairahawa, Rupandehi, Nepal.

\section{MATERIAL AND METHODS}

\section{Study design and source of population}

Hospital based cross-sectional study was conducted in pediatrics OPD of Universal College of Medical SciencesTeaching Hospital, Bhairahawa, Rupandehi, Nepal from September 2019 to March 2020. Mothers having child aged six to twelve months attending pediatrics OPD of UCMS Bhairahawa, Rupandehi, Nepal, who were willing to participate and can speak and understand Nepali language were included in the study. Similarly, those mothers who have severe mental problem, no willingness and did not speak and understand Nepali language were excluded during interview.

\section{Sample size determination and sampling technique}

Sample size was calculated using formula $N=Z^{2} p q / L^{2,8}$ with $95 \%$ level of confidence interval, $5 \%$ margin of error and $56.81 \%$ mothers fed their children complementary food of appropriate consistency. ${ }^{9}$ Initial sample size was 376. Considering $10 \%$ non-response rate, the final sample size was 414. A non-probability purposive sampling technique was used to select mothers of child age six to twelve months attending pediatrics OPD of UCMS-TH at Bhairahawa, Rupandehi, Nepal.

\section{Data collection procedures and validity}

Face to face interview was done using semi-structured questionnaire for collecting required data. Questionnaire was translated into Nepali and again retranslated into English language to find misinterpretation. Two-day training was provided to four pediatric residence doctors and one final year bachelor in public health student of UCMS. All the filled questionnaires were reviewed and checked by the principal investigator on regular basis.

\section{Data processing and analysis}

Data were entered into Microsoft excel and exported to Statistical Package for Social Science (SPSS) software version 20 for analysis. Characteristics of the sample were described using mean and standard deviation. Bivariate analysis was used primarily to assess the association between dependent and independent variables and those variables found to be associated with bivariate analysis $(p<0.05)$ were entered into the multivariate logistic regression model to identify the associated factors of level of knowledge of health promotional measures.

\section{Measurement of knowledge and practice regarding health promotional measures}

Health promotion measures index was made which was categorized as "poor knowledge" and "good knowledge" and cross tabulation analysis was done with independent variables. There were 20 questions related to knowledge regarding health promotional measure of infant. It consists of four sub-scales which comprised of knowledge regarding breast feeding, knowledge regarding complimentary feeding, knowledge regarding immunization and knowledge regarding prevention of accidents. The score of each sub scale was $6,5,5$ and 4 respectively. The total score for this section was 20 . The knowledge score was categorized as: Good knowledge: $\geq 50 \%$ of total score and Poor knowledge $<50 \%$ total score.

\section{Ethical consideration and informed consent}

Ethical approval was taken from Institutional Review 
Committee of UCMS and Teaching Hospital (UCMS/IRC /126/19). Moreover, all the participants were fully informed about the study. Written informed consent was taken from the respondents.

\section{RESULTS}

The mean age and family size was $25.89 \pm 4.81$ and $5.94 \pm 2.48$ respectively. From a total of 414 mothers more than threefourth (78\%) lived in sub metropolitan city and municipalities. About one-fourth $(23.7 \%)$ of the infant mothers had received education of secondary and above intermediate level. About half (49.3\%) of the infant father had receives education of intermediate and above level. Nearly half $(49.5 \%)$ of mothers were homemakers. About two-fifth $(39.4 \%)$ of infant fathers were engaged in small scale business (Table 1).

Table 1. Distribution of socio-demographic characteristics of study population

\begin{tabular}{|c|c|c|}
\hline \multirow{2}{*}{\multicolumn{3}{|c|}{$\begin{array}{l}\text { General Characteristics } \\
\text { Age }\end{array}$}} \\
\hline & & \\
\hline$\leq 20$ years & 58 & 14.0 \\
\hline$>20$ years & 356 & 86.0 \\
\hline \multicolumn{3}{|l|}{ Mean age $\pm S D ; 25.89 \pm 4.81$} \\
\hline \multicolumn{3}{|l|}{ Residence } \\
\hline Urban (Sub metropolitan city and municipalities) & 323 & 78.0 \\
\hline Rural (Rural municipalities) & 91 & 22.0 \\
\hline \multicolumn{3}{|l|}{ Family size } \\
\hline Lesser than equal to 5 & 228 & 55.1 \\
\hline Greater than 5 & 186 & 44.9 \\
\hline \multicolumn{3}{|l|}{ Mean family size $\pm S D ; 5.94 \pm 2.48$} \\
\hline \multicolumn{3}{|l|}{ Education of Mother } \\
\hline Illiterate and informal class & 81 & 19.6 \\
\hline Primary & 44 & 10.6 \\
\hline Secondary & 98 & 23.7 \\
\hline SLC & 93 & 22.5 \\
\hline Intermediate and above & 98 & 23.7 \\
\hline \multicolumn{3}{|l|}{ Education of Father } \\
\hline Illiterate and Informal class & 33 & 8.0 \\
\hline Primary & 41 & 9.9 \\
\hline Secondary & 63 & 15.2 \\
\hline SLC & 73 & 17.6 \\
\hline Intermediate and above & 204 & 49.3 \\
\hline \multicolumn{3}{|l|}{ Occupation of Father } \\
\hline Agriculture & 87 & 21.0 \\
\hline Small scale business & 163 & 39.4 \\
\hline Service (Government and private) & 134 & 32.4 \\
\hline Wage labor & 14 & 3.4 \\
\hline Foreign labor & 16 & 3.9 \\
\hline \multicolumn{3}{|l|}{ Birth space of index child } \\
\hline Lesser than equal to 2 years & 272 & 65.7 \\
\hline Greater than 2 years & 85 & 20.5 \\
\hline
\end{tabular}

Regarding knowledge of breast feeding more than four-fifth (93.2\%) of the infant's mother knew feeding only breast milk is breast feeding whereas nearly one fourth $(24.2 \%)$ of the infant's mother knew breast feeding should be done within one hour of birth. Likewise, more than three-fifth $(65 \%)$ of the infant's mother knew complementary feeding is the transition from exclusive breast feeding to family food whereas less than three fourth of the infant's mother knew that mashed cereals should be best in introducing complementary feeding and more than one-fourth $(27.1 \%)$ of the infant's mother knew that complimentary feeding should be given three to four times for infant. Similarly regarding immunization more than four-fifth $(85.3 \%)$ of the infant's mother knew that immunization provides immunity and protects against diseases and about half $(51.4 \%)$ of the infant mothers knew correctly about immunization schedule provided for $<1$-year infant. On the other hand, more than four-fifth $(90.8 \%)$ of the infant's mother knew about common accident for $<1$-year baby whereas about half $(53.6 \%)$ of the infant mothers knew that keeping everything in mouth is development facts leading to ingestion injury (Table 2).

Table 2. Distribution of knowledge regarding health promotional measure among mothers of infant

\begin{tabular}{|c|c|c|}
\hline Knowledge regarding health promotional measures & $\begin{array}{l}\text { Number } \\
(\mathrm{n}=414)\end{array}$ & Percenta \\
\hline \multicolumn{3}{|l|}{ Breast feeding } \\
\hline Knew feeding only breast milk is breast feeding & 386 & 93 \\
\hline Aware that breast milk is best nutrient for $<6$ months baby & 357 & 86.2 \\
\hline Knew breast feeding should be done within 1 hour of birth & 100 & 24.2 \\
\hline Knew colostrum feeding is necessary for every child & 352 & 85.0 \\
\hline Knew exclusive breast feeding should be done for 6 months & 249 & 60.1 \\
\hline Knew breast feeding should be continued for up to 2 years & 182 & 44.0 \\
\hline \multicolumn{3}{|l|}{ Complementary feeding } \\
\hline Aware about complementary feeding & 391 & 94.4 \\
\hline $\begin{array}{l}\text { Knew complementary feeding is the transition from exclusive breast feeding to } \\
\text { family food }\end{array}$ & 269 & 65.0 \\
\hline Knew that complementary feeding should be started after 6 months & 222 & 53.6 \\
\hline $\begin{array}{l}\text { Knew that mashed cereals should be best in introducing complementary } \\
\text { feeding }\end{array}$ & 290 & 70.0 \\
\hline Knew that complimentary feeding should be given 3 to 4 times for infant & 112 & 27.1 \\
\hline Immunization & & \\
\hline $\begin{array}{l}\text { Heard about immunization } \\
\text { Knew that immunization provides immunity and protects against diseases }\end{array}$ & $\begin{array}{l}413 \\
353\end{array}$ & $\begin{array}{l}99 . \\
85 .\end{array}$ \\
\hline Knew correctly about immunization schedule provided for $<1$ year infant & 213 & 51. \\
\hline Knew DPT vaccine should be start within 45 days & 249 & 60.1 \\
\hline Knew time intervals for DPT + Hep B + Hib B and Polio & 216 & 52 \\
\hline \multicolumn{3}{|l|}{ Prevention of accidents } \\
\hline $\begin{array}{l}\text { Knew that fall, ingestion, injury and burn are common accident for }<1 \text { year } \\
\text { baby }\end{array}$ & 376 & 90 \\
\hline Aware about prevention of ingestion injury among infants & 303 & 73. \\
\hline $\begin{array}{l}\text { Knew that keeping everything in mouth is development facts leading to } \\
\text { ingestion injury }\end{array}$ & 222 & 53 \\
\hline Knew that child should not be left alone in order to prevent from fall accidents & 317 & 76 \\
\hline
\end{tabular}

About three-fourth (73.2\%) of the mothers of infants have good knowledge regarding health promotional measure (Table 3). 
Table 3. Distribution of mothers of infant knowledge grading on health promotional measures

\begin{tabular}{lcr}
\hline Characteristics & Frequency $(\mathbf{n}=414)$ & Percentage \\
\hline Poor knowledge & 111 & 26.8 \\
Good knowledge & 303 & 73.2 \\
Total & 414 & 100.0 \\
\hline
\end{tabular}

Table 4 showed socioeconomic, socio-demographic and child related factors associated with knowledge level of health promotional measures. Those variables which were found statistical significant with $p$ value lesser than equal to 0.05 in bivariate analysis, were entered into the multivariate regression analysis model which identified age of respondents, ethnicity, residence of living, family size, mother's education, father's education, father's occupation and birth space of two child as associated factors with knowledge level of health promotional measures. Mothers who were greater than 20 years were 8.13 times more likely (AOR= $8.13, \mathrm{CI}=2.16-30.67$ ) to have good knowledge regarding health promotional measures. The odds of having good knowledge regarding health promotional measures were less among mothers who were from Dalit caste $(\mathrm{AOR}=0.02, \mathrm{CI}=$ $0.003-0.16)$ and who live in the rural area $(\mathrm{AOR}=0.27$, $\mathrm{CI}=0.08-0.61)$. Mothers having $>5$ members in the family were 3.99 times more likely $(\mathrm{AOR}=8.13, \mathrm{CI}=1.37-11.59)$ and having educational backgrounds below SLC level were 0.29 times less likely $(\mathrm{AOR}=0.29, \mathrm{CI}=0.094-0.88)$ to have good knowledge regarding health promotional measures. However, the odds of having good health promotional measures were high among fathers who were from SLC and above backgrounds $(A O R=25.40, C I=4.54-142.0)$, engaged in other than agriculture work $(\mathrm{AOR}=4.78, \mathrm{CI}=1.80-12.68)$ and whose index child had birth space of greater than two years $(\mathrm{AOR}=5.88, \mathrm{CI}=1.48-23.35)($ Table 4$)$.

Table 4. Factors associated with knowledge level of health promotion in bivariate and multivariate analysis

\begin{tabular}{|c|c|c|c|c|c|}
\hline \multirow[t]{2}{*}{ Characteristics } & \multicolumn{2}{|c|}{ Knowledge Level (\%) } & \multirow[b]{2}{*}{$p$-value } & \multirow[t]{2}{*}{${ }^{\mathrm{a}} \mathrm{COR} 95 \% \mathrm{CI}$} & \multirow[t]{2}{*}{${ }^{\mathrm{b}} \mathrm{AOR} 95 \% \mathrm{CI}$} \\
\hline & $\begin{array}{l}\text { Poor } \\
\text { knowledge }\end{array}$ & $\begin{array}{l}\text { Good } \\
\text { knowledge }\end{array}$ & & & \\
\hline \multicolumn{6}{|c|}{ Age of respondents } \\
\hline$\leq 20$ years & $22(37.9)$ & $36(62.1)$ & & 1 & 1 \\
\hline$>20$ years & $89(25.0)$ & $267(75.0)$ & $0.039^{*}$ & $1.83(1.024-3.28)$ & $8.13(2.16-30.67)$ \\
\hline \multicolumn{6}{|l|}{ Ethnicity } \\
\hline Brahmin/Chhetri & $22(15.2)$ & $123(84.8)$ & & 1 & 1 \\
\hline Madeshi & $18(20.2)$ & $71(79.8)$ & $<0.001^{*}$ & $0.71(0.36-1.40)$ & $1.13(0.37-3.43)$ \\
\hline Dalits & $21(75.0)$ & $7(25.0)$ & & $0.06(0.02-0.15)$ & $0.02(0.003-0.16$ \\
\hline Newar & $5(21.7)$ & $18(78.3)$ & & $0.64(0.22-1.92)$ & $0.53(0.08-3.31)$ \\
\hline Janjati & $17(28.8)$ & $42(71.2)$ & & $0.44(0.21-0.91)$ & $0.52(0.12-2.21)$ \\
\hline Muslim & $28(40.0 \%)$ & $42(60.0)$ & & $0.27(0.14-0.52)$ & $0.35(0.05-2.72)$ \\
\hline \multicolumn{6}{|l|}{ Residence } \\
\hline Urban & $74(22.9)$ & $249(77.1)$ & & 1 & 1 \\
\hline Rural & $37(40.7)$ & $54(59.3)$ & 0.001 & $0.43(0.27-0.71)$ & $0.27(0.08-0.61)$ \\
\hline \multicolumn{6}{|l|}{ Religion } \\
\hline Hindu & $78(23.5)$ & $254(76.5)$ & & 1 & 1 \\
\hline Non Hindu & $33(40.2)$ & $49(59.8)$ & $0.002^{*}$ & $0.46(0.27-0.76)$ & $0.44(0.07-2.90)$ \\
\hline \multicolumn{6}{|l|}{ Size of family } \\
\hline$\leq 5$ members & $47(20.6)$ & $181(79.4)$ & & 1 & 1 \\
\hline$>5$ members & $64(34.4)$ & $122(65.6)$ & $0.002^{*}$ & $0.50(0.32-0.77)$ & $3.99(1.37-11.59)$ \\
\hline
\end{tabular}

\begin{tabular}{|c|c|c|c|c|c|}
\hline \multicolumn{6}{|l|}{ Mother's Education } \\
\hline Illiterate and informal & $48(59.3)$ & $33(40.7)$ & & 1 & 1 \\
\hline Below SLC & $45(31.7)$ & $97(68.3)$ & & $3.14(1.78-5.53)$ & $0.29(0.094-0.88)$ \\
\hline SLC and above & $18(9.4)$ & $173(90.6)$ & $<0.001^{*}$ & $13.98(7.25-26.98)$ & $1.09(0.25-4.73)$ \\
\hline \multicolumn{6}{|l|}{ Father's Education } \\
\hline Illiterate and informal & $27(81.8)$ & $6(18.2)$ & & 1 & 1 \\
\hline Below SLC & $53(51.0)$ & $51(49.0)$ & $<0.001^{*}$ & $4.33(1.65-11.36)$ & $2.16(0.38-12.20)$ \\
\hline $\begin{array}{l}\text { SLC and above } \\
\text { Father's Occupation }\end{array}$ & \multicolumn{4}{|c|}{ Father’s Occupation } & $25.40(4.54-142.0)$ \\
\hline Agriculture & $44(50.6)$ & $43(49.4)$ & & 1 & 1 \\
\hline Other than Agriculture & $67(20.5)$ & $260(79.5)$ & $<0.001^{*}$ & $3.97(2.41-6.54)$ & $4.78(1.80-12.68)$ \\
\hline \multicolumn{6}{|l|}{ Live with } \\
\hline Parents & $97(25.4)$ & $285(74.6)$ & & 1 & 1 \\
\hline Relatives & $14(43.8)$ & $18(56.3)$ & $0.024 *$ & $0.44(0.21-0.91)$ & $1.17(0.37-3.68)$ \\
\hline \multicolumn{6}{|l|}{ Sex of latest child } \\
\hline Male & $44(19.7)$ & $179(80.3)$ & & 1 & 1 \\
\hline Female & $67(35.1)$ & $124(64.9)$ & $<0.001^{*}$ & $0.46(0.29-0.71)$ & $0.47(0.20-1.12)$ \\
\hline \multicolumn{6}{|l|}{$\begin{array}{l}\text { Birth space (index } \\
\text { child) }\end{array}$} \\
\hline$\leq 2$ years & $74(27.2)$ & $198(72.8)$ & & 1 & \\
\hline $\begin{array}{l}>2 \text { years } \\
\text { Food security }\end{array}$ & $11(12.9)$ & $74(87.1)$ & $0.007^{*}$ & $2.51(1.26-4.99)$ & $5.88(1.48-23.35)$ \\
\hline$\leq 6$ months & $94(34.4)$ & $179(65.6)$ & & 1 & 1 \\
\hline$>$ months & $17(12.1)$ & $124(87.9)$ & $<0.001^{*}$ & $3.83(2.18-6.74)$ & $2.63(0.85-8.16)$ \\
\hline
\end{tabular}

*Significant at $p<0.05,1=$ Reference category, ${ }^{a}$ Crude odds ratio, ${ }^{\mathrm{b}}$ Adjusted odds ratio

\section{DISCUSSION}

Age of respondents, ethnicity, residence of living, family size, mother's education, father's education, father's occupation and birth space of two children were associated factors of good knowledge of health promotional measures in this study. About three-fourth of the infant mothers had good knowledge on health promotional measures, however another study conducted in Nepal found lower portion of the mothers had good knowledge. ${ }^{10}$ This disparity might be due to divergence scoring system for measuring the health promotional measures.

The present study revealed that less than one-fourth of the respondents knew that breast feeding should be done within an hour of birth, however another study done in Nepal found higher portion of the mothers were aware about the time of feeding colostrum. ${ }^{11}$ Majority of the mothers, in this study knew that colostrum feeding is necessary for every child, in contrast to this another study conducted in Kathmandu, Nepal found that lower proportion of the women knew colostrum is nutritious for new born babies. ${ }^{11}$ This difference might be due to progression of educational supplies as compared to previous time. Three-fifth of the respondents have knowledge on duration of exclusive breastfeeding which is in line with the study done in Nigeria, ${ }^{12}$ however another study conducted in Dhaka, Bangladesh found higher proportion of the mothers have good knowledge on duration of exclusive breastfeeding. ${ }^{13}$ Less than half of the mothers knew that breastfeeding should be continued for up to two years which is inconsistent with the several other studies such as study done in India ${ }^{14}$ and Dhaka, Bangladesh. ${ }^{13}$

Most of the mothers in this study were aware about 
complementary feeding which is in line with the study conducted in Nepal. ${ }^{15}$ About two-third of the respondents in this study knew that complementary feeding is the transition from exclusive breast feeding to family food which is in line with the study conducted in Nigeria. ${ }^{16}$ In this study more than half of the respondents knew about the recommended time for starting complementary feeding which is in line with the study conducted by Aggarwal A, et $\mathrm{al}^{17}$ however several other studies such as study conducted in Nepal ${ }^{18,19}$ and Nigeria ${ }^{16}$ found higher portion of the mothers knew that complementary feeding should be started at six months of age.

Most of the respondents in this study have heard about immunization which is in line with several other studies such as study done in Indonesia ${ }^{20}$ and Ethiopia. ${ }^{21,22}$ Majority of the respondents in this study knew that immunization provides immunity and protects against diseases which is supported by the study conducted in Pakistan. ${ }^{23}$

Majority of mothers were aware that fall, ingestion, injury and burn are common accident for lesser than one year baby which is inconsistent with study conducted in Nepal. ${ }^{24}$ More than three-fourth of the respondents in the present study knew that child should not be left alone in order to prevent from fall accidents, in contrast to this study most of respondents in the study done in Nepal were aware that lack of supervision can cause home accident to infants. ${ }^{24}$

In this study, age of the respondents was statistically significant with knowledge of health promotional measures which is in accordance with the study conducted in Nigeria where knowledge of complementary feeding was associated with mothers' age. ${ }^{16}$ The present study found education of mother was associated with knowledge of health promotional measures which is in accordance with the study done in Bangladesh where mothers' education is associated with a knowledge score of breastfeeding. ${ }^{13}$ Residence of living in this study was statistically significant with knowledge of health promotional measures which is inconsistent with the study done in Pakistan where residence of living was not significantly associated with knowledge of complementary feeding. ${ }^{25}$

\section{CONCLUSIONS}

Age of mother, caste, residence, family size, education of mother and father, occupation of father and birth space of index child were found to be independent associated factors of knowledge of health promotional measures. In this context, it is recommended that administrators and policy makers should provide specific education regarding health promotional measures to both the parents focusing on rural area. Similarly, local Government needs to subsidize in reducing teenage marriage.

\section{CONFLICT OF INTEREST}

There is no conflict of interest.

\section{List of abbreviations}

AOR: Adjusted odds ratio; CF: Complementary feeding, CI: Confidence interval; COR: Crude Odds ratio; SD: Standard Deviation; SLC: School leaving certificate; SPSS: Statistical package for the social sciences, UCMS: Universal College of Medical Sciences.

\section{ACKNOWLEDGEMENT}

The authors would like to express their deepest gratitude to Universal College of Medical Sciences for necessary administrative arrangement by providing financial support for the study. Authors would also like to express their deepest gratitude to Dr. Ashraya Kedria, Dr. Sanjeev Shah, Dr. Astha Poudel and Dr. Ranjana Sharma pediatric residents and Ms. Ankita Kunwar final year Bachelor in Public Health student for their support in data collection. Last but not least, we would like to remember all participants for their valuable time and support for providing inevitable information for the study.

\section{REFERENCES}

1. Dutta P. Peadiatric Nursing (Third ed.). New Delhi India. Jaypee Brothers Medical Publishers (p) Ltd. 2014.

2. Peggyl, Chhina Infants and early childhood, childhood maintenance, 2nd edition, The CV Mosby Company. 1997.

3. Santé Omdl, Staff WHO, Organization WH, UNICEF, UNAIDS. Global strategy for infant and young child feeding: World Health Organization; 2003.

4. Subedi N, Paudel S, Rana T, Poudyal A. Infant and young child feeding practices in Chepang communities. Journal of Nepal Health Research Council. 2012;10(21):141-146.

5. NDHS. Ministry of Health, Nepal; New ERA; and ICF. Nepal Demographic and Health Survey 2016. Kathmandu, Nepal: Ministry of Health, Nepal. Kathmandu, Nepal.

6. WHO Immunization coverage fact sheet 2016. Available from https://www.who.int/news-room/fact-sheets/detail/ immunization-coverage

7. Center for disease control and preventon. Protect the once you love: child injuries are preventable. 2008. Available from, https:// www.cdc.gov/safechild/child_injury_data.html.

8. Daniel WW, Cross CL. Biostatistics: A foundation for analysis in the health sciences: Wiley. 2018.

9. Chapagain R. Factors affecting complementary feeding practices of Nepali mothers for 6 months to 24 months children. Journal of Nepal Health Research Council. 2013;11(24):205-207 
10. Lamichhane K, Maharjan S, Kachapati A. Awareness regarding health promotion of infants among mothers of Rupandehi, Nepal. Journal of Universal College of Medical Sciences. 2020;8(1):6064.

11. Joshi SK, Barakoti B, Lamsal S. Colostrum feeding: Knowledge, attitude and practice in pregnant women in a teaching hospital in Nepal. Webmed Central Medical Education. 2012;3(8) :wmc003601.

12. Peterside O, Kunle-Olowu E, Duru O. Knowledge and practice of exclusive breast feeding among mothers in Gbarantoru community, Bayelsa state, Nigeria. J Dent Med Sci. 2013;12(6) $: 34-40$.

13. Afrose L, Banu B, Ahmed KR, Khanom K. Factors associated with knowledge about breastfeeding among female garment workers in Dhaka city. World Health Organization. 2012 ;1(3):249-255.

14. Memon S, Shaikh S, Kousar T, Memon Y, Rubina Y. Assessment of infant feeding practices at a tertiary care hospital. Journal of the Pakistan Medical Association. 2010;60(12):1010-15.

15. Koirala S, Koirala M. Awareness and practice of mothers regarding health promotion of under-five children in urban slum area of Kathmandu. Journal of Institute of Medicine. 2015;37 (2):72-78.

16. Olatona FA, Adenihun JO, Aderibigbe SA, Adeniyi OF. Complementary feeding knowledge, practices, and dietary diversity among mothers of under-five children in an urban community in Lagos State, Nigeria. International Journal of $\mathrm{MCH}$ and AIDS. 2017;6(1):46-59.

17. Aggarwal A, Verma S, Faridi M. Complementary feeding reasons for inappropriateness in timing, quantity and consistency. The Indian Journal of Pediatrics. 2008;75(1):49.

18. Basnet S, Sathian B, Malla K, Koirala DP. Reasons for early or late initiation of complementary feeding: A study in Pokhara. Am J Public Health Res. 2015;3(4A):69-75.

19. Chapagain RH. Complementary feeding practices of Nepali mothers for 6 months to 24 months children. Journal of Nepal Medical Association. 2013;52(191):443-8.

20. Kim S, Singarimbun M. Social factors affecting use of immunization in Indonesia. Social Science \& Medicine. 1988;27 (11):1237-45.

21. Legesse E, Dechasa W. An assessment of child immunization coverage and its determinants in Sinana District, Southeast Ethiopia. BMC Pediatrics. 2015;15(1):31.

22. Etana B, Deressa W. Factors associated with complete immunization coverage in children aged 1223 months in Ambo Woreda, Central Ethiopia. BMC Public Health. 2012;12(1):566.

23. Gul S, Khalil R. Immunisation knowledge and practices among mothers attending a paediatric clinic in Karachi, Pakistan. International Journal of Advances in Medicine. 2016;3(3):656661.
24. Adhikari B, Bhattarai S, Gauro P, Mishra R. Awareness and practice of mother having under five children regarding prevention of childhood accident. International Journal of Health Sciences and Research. 2017;7(9):134-144.

25. Hasnain S, Majrooh MA, Anjum R. Knowledge and practices of mothers for complementary feeding in babies visiting Pediatrics outpatient department oF Jinnah HospitaL, Lahore. Biomedica. 2013;29(4):221-230. 